\title{
DESTAQUE EDITORIAL
}

\section{OS DIREITOS DAS MULHERES NA LEGISLAÇÃO BRASILEIRA PÓS- CONSTITUINTE - LEGISLAÇÃO (FEDERAL, ESTADUAL E MUNICIPAL) SOBRE DIREITOS DAS MULHERES A PARTIR DA CONSTITUIÇÃO DE 1988}

Almira Rodrigues; láris Ramalho Cortês (orgs.)

Brasília: CFÊMEA, Letras Livres, 2006. $128 p$.

A publicação foi produzida pelo Centro Feminista de Estudos e Assessoria - CFEMEA -, que há 16 anos monitora a legislação brasileira no que se refere ao combate às desigualdades e procura incidir nos processos de construção de marcos legais. $\bigcirc$ estudo foi subproduto do projeto "Gestão em Gênero", empreendido pela organização em parceria com a Secretaria Especial de Políticas para as Mulheres - SEPM, e elaborado como o intuito de avaliar a legislação federal sobre igualdade de gênero e cidadania das mulheres, tendo como referência a Constituição Federal de 1988. No entanto, não se restringe a esta, procurando analisar a legislação federal que a regulamenta, como o Estatuto da Criança e do Adolescente, dos Idosos e da Igualdade Racial, tomando o período de 1988 a 2005. Também inclui um estudo sobre as Constituições Estaduais, realizado por Eneida Vinhaes Bello Dutra e destaques das legislações estaduais e municipais, de autoria de Giane Boselli.

Logo no começo, é ressaltada a importância da legislação na sociedade, afirmando que esta "nos diz sobre os acordos de uma sociedade consigo mesma, regulando as relações, as instituições e os processos sociais" (p. l l). Isso porque freqüentemente se aponta que a legislação brasileira é avançada em termos de direitos e cidadania, mas apresenta uma realidade ainda muito distante da letra da lei. As autoras, no entanto, lembram que os avanços legais são conquistas resultantes de embates políticos e ideológicos que devem ser comemorados, pois, mesmo quando não cumpridos, tornam-se importantes, tanto por serem expressão do "desejo de pautar novas realidades sociais", como por serem uma "referência fundamental para a ação de sujeitos políticos" (p. I2). Estes incluem as organizações da sociedade civil (movimentos sociais e ONGs) e partidos políticos. A luta para efetivação de direitos "demanda, portanto, mobilizações, estratégias, e forte interlocução com os poderes constituídos" (p. | 2).

Por fim, há o aspecto processual da conquista de direitos legais, que ao longo dos anos foram sendo "conquistados e ampliados". No entanto, esse desenvolvimento não garante que os direitos sejam assegurados, o que "alude à necessidade de organização e constante mobilização social para se fazer frente também à possibilidade de perda e restrição de direitos conquistados" (p. |2).

Nesse sentido, as autoras ressaltam que Constituição Federal de 1988 foi um marco na conquista de direitos das mulheres, em que, pela primeira vez, é expressa a igualdade jurídica entre homens e mulheres no ordenamento jurídico brasileiro. Também aprofunda e cria novos direitos, além de novas obrigações do Estado.

A obra é subdividida em três partes. A primeira, sobre a legislação federal, é dividida 
em 12 temas específicos: Direitos Humanos, Direitos Civis, Violência, Saúde, Educação, Trabalho, Previdência Social, Assistência Social, Habitação e Desenvolvimento, Ciência e Tecnologia e Meio Ambiente, Política e Poder, Controle Social e Orçamento Público, complementados com um tópico sobre os instrumentos internacionais assinados pelo Brasil - que podem ser interpretados como dispositivo constitucional após a Emenda Constitucional 45 -, além de considerações e recomendações finais sobre o conteúdo analisado.

A segunda parte - "Questões de Gênero nas Constituições Estaduais: similitudes, avanços e omissões a partir da Constituição Federal de 1988" - , além de ser dividida em temas, de forma semelhante ao capítulo anterior, com exceção do tópico "Ciência Tecnologia e Meio Ambiente", também traz comentários específicos sobre as constituições de cada estado.

A terceira parte subdivide-se em dois tópicos, "Leis Estaduais" e "Leis Municipais" e ambos contém três partes cada um: "Tipos de Legislação", "Impacto da Legislação" e "Análise da Legislação segundo Temáticas".

Ao final, a publicação traz quadros-resumo de toda a legislação analisada. Além da análise da legislação federal, procura também apontar lacunas, tendo como parâmetro as reivindicações dos movimento de mulheres, em especial aquelas expressas na I Conferência Nacional de Mulheres Brasileiras (2002) e na I Conferência Nacional de Políticas paras Mulheres (2004). Apesar de não ter contemplado a recente Lei Maria da Penha, de enfrentamento à violência doméstica e familiar, devido ao período abordado, trata-se, de publicação de referência, importante e ampla, a respeito dos direitos legais das mulheres no Brasil.

\section{DIMENSÕES DA INCLUSÃO NO ENSINO MÉDIO: MERCADO DE TRABALHO, RELIGIOSIDADE E EDUCAÇÃO QUILOMBOLA}

\section{(Coleção Educação para todos, 9)}

Maria Lúcia de Santana Braga, Edileuza

Penha de Souza, Ana Flávia Magalhães

Pinto (orgs.)

Brasília: Ministério da Educação,

Secretaria de Educação Continuada,

Alfabetização e Diversidade, 2006, 364 p.

Este livro faz parte da Coleção Educação para todos, lançada pelo Ministério da Educação e pela Unesco em 2004, com vistas à divulgação de textos, documentos, relatórios de pesquisa e outros estudos e eventos que propiciam uma interlocução com educadores e gestores da área educacional.

A coleção reafirma o propósito de inclusão social dos milhões de jovens e adultos marginalizados pelos processos de aprendizagem formal não só no Brasil como em outras partes do mundo.

O livro em apreço traz um conjunto de artigos que resultaram da pesquisa "Realidade de estudantes negros no ensino médio" que abrangeu as cinco regiões do país. Focaliza os seguintes temas: expectativas de inserção no mercado de trabalho desses jovens, tendo em conta também a questão do gênero; a religiosidade afro-brasileira e o espaço escolar; aspectos da educação formal e não formal nas comunidades negras rurais.

Representa contribuição valiosa na busca de suprir lacunas acerca do entendimento da realidade sociorracial no país. 


\section{GESTÃO DE INOVAÇÕES NO ENSINO MÉDIO (ARGENTINA/ BRASIL/ESPANHA)}

Maria Rosa Almandoz et al. Ana Vitar, Dagmar M. L. Zibas; Celso J. Ferretti; Gisela Lobo B. P. Tartuce (orgs.) Brasilia: Líber Livro Editora, 2006. 200 p.

título dessa publicação reúne três temas: gestão, inovação e ensino médio, que têm gerado, há mais de uma década, controvérsias, debates e propostas as mais diversas em diferentes países. De fato, a gestão tornou-se, nos anos 1990, o leitmotif de recomendações de agências internacionais, baseadas principalmente no argumento de que os problemas dos sistemas de ensino não seriam decorrentes sobretudo da falta de investimentos, mas, sim, da ineficiência de gestão sistêmica e institucional.

Adicionalmente, em tempos de implementação de diversas reformas educacionais, o conceito de inovação tem provocado discussões e suscitado projetos da mais variada natureza, quase sempre, tendo faltado consenso quanto à definição do que poderia ser considerada uma inovação educacional e sobre a relação entre inovação e reforma.

Quanto ao ensino médio, a sua reforma esteve na pauta política de muitos países nos anos 1990 e, embora com muitas diferenças, os projetos nacionais apresentaram também diversas convergências, principalmente na tentativa de adequar os sistemas de ensino às novas necessidades da produção e de construir subjetividades que suportassem as condições cada vez mais adversas de competição no mercado de trabalho e de desemprego.

Com tal apelo, o livro em questão traz resultados de três pesquisas, desenvolvidas na Argentina, no Brasil e na Espanha, as quais, financiadas pela Organização do Estados Ibero-ame- ricanos - OEI -, procuraram desvelar a trama social, política e pedagógica que constrói os caminhos e descaminhos das propostas oficiais, tanto no nível institucional quanto no sistêmico.

artigo de Liliana Sinisi, da Universidade de Buenos Aires, debate o Programa de fortalecimento institucional em escolas do ensino médio da Argentina e traz importantes subsídios para a discussão de políticas públicas que tentam, de alguma forma, promover a aproximação entre mecanismos de mercado e a dinâmica escolar. Além disso, o texto analisa em que medida e de que forma a constituição histórica de cada unidade escolar dirige os processos institucionais de apropriação das inovações propostas pelos órgãos oficiais.

Dagmar M. L. Zibas, Celso J. Ferretti e Gisela Lobo B. P. Tartuce assinam artigo que discute resultados de pesquisa focalizada na reforma do ensino médio sob o prisma do protagonismo de alunos e pais. A problematização do conceito, tanto na literatura quanto no texto da reforma, constitui um aspecto importante da abordagem e ilumina a discussão dos dados recolhidos em cinco escolas de dois estados brasileiros.

texto dos professores da Universidade de Valência - Francisco Beltrán Llavador, Francisco J. Jódar Rico e Ángel San Martin Alonso - divulga resultados de estudo voltado para a análise das estratégias colocadas em jogo pelas escolas responsáveis pela implementação do princípio de compreensividade que acompanhou a adoção do ensino secundário obrigatório na Espanha. O significado político e pedagógico da "compreensividade" é discutido em face das tramas institucionais que adotam, resistem às diretrizes oficiais ou as recriam.

As pesquisas divulgadas pelo livro são precedidas de artigo de Maria Rosa Almandoz, atual Diretora Executiva do Instituto Nacional de Educação Técnica do Ministério da Educação da Argentina, e de Ana Vitar, especialista em 
políticas educacionais da OEl. Além de esclarecer os objetivos desse organismo ao financiar os estudos, as autoras discutem com pertinência e profundidade os conceitos que embasaram o projeto-matriz que deu origem os trabalhos desenvolvidos nos três países.

Enfim, trata-se de publicação com uma característica não muito comum no mundo editorial da área da educação: traz uma variedade de olhares e temas específicos que remetem à questões importantes para as respectivas realidades educacionais, mas, ao mesmo tempo, privilegia o terreno comum por onde transitam as perplexidades e as contradições globalmente partilhadas nestes tempos de fragilização das identidades nacionais. 